\title{
Do império do olhar à arte de ver
}

\author{
JOÃO AUGUSTO FRAYZE-PEREIRA
}

RESUMO: Martin Jay (1986) e John Rajchman (1988) escreveram ensaios sobre o espaço da visão e do visual na obra de Foucault. Porém, se a questão é a mesma, o modo de ver dos autores é oposto. Interrogando esses dois ensaios, este artigo pretende configurar uma outra visão sobre o império do olhar e a arte de ver nos escritos de Foucault. A relação entre visão e pensamento é considerada na perspectiva das problematizações.

mpério do Olhar e Arte de Ver são expressões que aparecem nos títulos de dois ensaios sobre Foucault. O primeiro é de Martin Jay, publicado pela primeira vez, em Londres, em 1986. O segundo é de John Rajchman, publicado em Nova York, em 1988. Ambos tratam de um mesmo tema: o espaço da visão e do visual na obra de Foucault. No entanto, se o tema é o mesmo, o modo de ver dos comentadores é diverso, oposto. E é a nossa intenção, ou pretensão, interrogar a relação entre os dois para ver melhor o sentido do olhar e a expressão do ver em alguns escritos de Foucault.

Não nos parece necessário, nesse momento, fazer um comentário sobre a importância da visão na Filosofia, especialmente na Filosofia Francesa, de Descartes ao próprio Foucault. Apenas como um lembrete e tendo por referência alguns pensadores contemporâneos, por exemplo, a questão do visível e do olhar pode ser encontrada, largamente tematizada, nas obras de Merleau-Ponty, Sartre, Derrida, Barthes, Lyotard, Sarah Koffman, Louis Marin, Deleuze, Starobinski, entre outros. E, além dos filósofos, pode-se acrescentar toda uma lista de poetas (Baudelaire, Valéry, Appolinaire, Reverdy, todos os surrealistas, Ponge e Bonnefoy) e, é claro, também alguns romancistas como,
UNITERIMOS:

Foucault, olhar, visão, visão-pensamento, arte de ver.

Professor do Departamento de Psicologia Social e do Trabalho do IP- USP 
por exemplo, Robbe Grillet e Michel Tournier. Quer dizer, Martin Jay (1989, p. 199) apóia-se nas obras de autores como esses e de outros mais para afirmar - há uma "obsessão pelo visual entre os franceses". E dela Foucault não escapou. Mas, fez a crítica do visual e dos poderes do olhar, elaborando um discurso que se pode designar, com base em Jay (1989), "antivisão".

Ora, a fascinação de Foucault pelo visual está presente desde o início de sua carreira, como se pode notar lendo a biografia escrita por Didier Eribon (1990). Essa fascinação coincide com seus primeiros interesses pela Fenomenologia de Merleau-Ponty, pela Ontologia de Heidegger e, sobretudo, pela Psicanálise Existencial de Binswanger. São pensadores que repudiam radicalmente o tradicional primado cartesiano de um sujeito contemplativo, separado do mundo. Tanto em Binswanger quanto em Merleau-Ponty surge a idéia de uma visão encarnada, cruzamento reversível do visível e do invisível, do vidente e do visível, na carne do mundo que poderia ser o princípio de um sentido positivo. Foucault escutou atentamente a face oculta da hegemonia do visual. E bem antes de sua crítica ao Panoptismo - crítica que se tornou célebre e influente - seus escritos dos anos 60 testemunham a sua consciência do primado do visual e de suas sinistras implicações. História da loucura (1961), O nascimento da clínica (1963) e As palavras e as coisas (1966) são marcos dessa notável apreensão.

Na História da loucura, Foucault (1972) começa a análise mostrando que a constituição da loucura moderna principia com a dissolução da unidade palavra-imagem - unidade presente na Idade Média e no Renascimento e que, ao se desfazer, dará margem à emergência de figuras da loucura desprovidas de toda e qualquer significação escatológica. Escreve Foucault: "entre o verbo e a imagem, entre aquilo que é figurado pela linguagem e aquilo que é dito pela plástica, a bela unidade começa a se desfazer: uma única e mesma significação não lhes é imediatamente comum. (...) Figura e palavra ilustram ainda a mesma fábula de loucura no mesmo mundo moral; mas logo tomam duas direções diferentes, indicando, numa brecha ainda apenas perceptível, aquela que será a grande linha divisória na experiência ocidental da loucura" (Foucault, 1972, p. 28).

Ora, para o espírito clássico, a essência da loucura era a cegueira, um termo que "fala dessa noite de quase-sono que envolve as imagens da loucura, atribuindo-lhes, em seu isolamento, uma invisível soberania; mas fala também de crenças mal fundamentadas, juízos que se enganam, de todo esse pano de fundo de erros inseparável da loucura" (Foucault, 1972, p. 260). E, nesse sentido, a loucura era, também, ofuscamento que significa "a noite em pleno dia, a obscuridade que reina no próprio centro do que existe de excessivo no brilho da luz (...). Dizer que a loucura é ofuscamento é dizer que o louco vê o dia, o mesmo dia que vê o homem de razão (ambos vivem na mesma claridade), mas vendo esse mesmo dia, nada além dele e nada nele, vêo como vazio, como noite, como nada (...). E, acreditando ver, permite que venham até ele, como realidades, os fantasmas de sua imaginação e todos os 
FRAYZE-PEREIRA, João Augusto. Do império do olhar à arte de ver Tempo Social; Rev. Sociol. USP, S. Paulo, 7(1-2): 151-162, outubro de 1995.

habitantes das noites". Em suma, delírio e ofuscamento formam uma relação que constitui a essência da loucura, na mesma medida que o relacionamento verdade-clareza constitui a razão clássica. "Descartes fecha os olhos e tapa os ouvidos para melhor ver a verdadeira claridade do dia essencial; com isso, garante-se contra o ofuscamento do louco que, abrindo os olhos, vê apenas a noite e, nada vendo, acredita ver quando na verdade imagina" (Foucault, 1972, p. 262). Ora, se o círculo do dia e da noite, como resume Foucault, circunscreve o mundo clássico, "o desatino mantém a mesma relação com a razão que o ofuscamento com o brilho do dia. E isto não é uma metáfora. Estamos no centro da grande cosmologia que anima toda a cultura clássica". Porém, é quando nasce o asilo, entre o fim do século XVIII e o começo do XIX, que a definição visual da loucura se estreita e atinge um limite: no asilo, a loucura só existe como ser visto..."1. Trata-se de um momento concreto na gênese da loucura moderna, momento que é da "ordem da observação e da classificação" e que supõe a estranheza dos corpos dos internados oferecidos à visão plena de um público burguês ávido de diversão.

Com efeito, durante o século XVIII, o hábito de exibir publicamente a loucura em carne e osso, possuía um caráter quase institucional. Quando havia bom tempo, Bicêtre chegava a receber 2000 pessoas por dia que pagavam para ver "um padre irlandês que 'dormia na palha', um capitão de navio que ficava furioso vendo homens, 'pois tinha sido a injustiça dos homens que o havia tornado louco', um jovem 'que cantava de modo encantador"' (Foucault, 1972, p. 162). Acima do silêncio dos asilos, a loucura é configurada em espetáculos nos quais os loucos são monstros, isto é, "seres ou coisas que merecem ser mostrados". E, nessas exposições, não há o que temer: a visão que deles se tem distrai. Coisa a ser vista, é do outro lado das grades que a loucura é exibida: " animal de estranhos mecanismos, bestialidade da qual o homem, há muito tempo, está abolido” (p.163). Assim, diante do espectador a loucura encontra-se do outro lado - ela é uma ausência total de razão. E sob o seu olhar - o louco é uma individualidade singular cujas características próprias distinguem-se daquilo que é encontrável no não-louco, isto é, no indivíduo razoável que é o seu juiz. Para este, o louco é, portanto, o outro (no sentido da exceção) entre os outros.

Com o advento do asilo, o louco e o não-louco encontram-se mais próximos. A barreira das grades é abolida. No entanto, mais do que nunca a loucura adquire o estatuto de algo a olhar-se. Se na loucura (como uma realidade cognoscível) há algo que diz respeito ao indivíduo razoável, não é porque a loucura contesta para ele a totalidade do ser humano, mas porque contribui para aquilo que se pode saber do homem. "Não é por acaso (...) que o século XIX perguntou inicialmente à patologia da memória, da vontade e da pessoa o que era a verdade da lembrança, do querer e do indivíduo" (Foucault, 1972, p. 481). Isto é, o louco ganhou o estatuto de um documento vivo. Através dele, pode-se chegar a um conhecimento do homem. E essa condição é enigmática, pois ao mesmo tempo que é objeto de conhecimento, a loucura
1 A relação entre a loucura, a visão e o visual encontra-se tematizada mais amplamente em Frayze-Pereira, J. A. (1995). 
oferece ao homem a possibilidade de um auto-reconhecimento. A contemplação da loucura adquire um novo sentido.

"Na época das visitas a Bicêtre ou a Bedlam, ao olhar-se o louco avaliava-se, do exterior, toda a distância que separava a verdade do homem de sua animalidade. Agora, ele é olhado simultaneamente com mais neutralidade e mais paixão. Mais neutralidade, uma vez que nele se descobrirão as verdades profundas do homem, essas formas adormecidas nas quais nasce aquilo que ele é. E mais paixão também, uma vez que não se poderá reconhecê-lo sem reconhecer a si mesmo, sem ouvir subir em si mesmo as mesmas vozes e as mesmas forças, as mesmas estranhas luzes" (Foucault, 1972, p. 537). Esse olhar que promete a contemplação de uma verdade do homem não pode evitar o espetáculo de um impudor que é o seu próprio: não vê sem ver a si mesmo. E, com isso, o louco fortalece seu poder de atração e fascinação, pois carrega mais verdades do que a sua própria. Contudo, com as promessas de conhecimento e cura que o asilo passou a oferecer, o costume de exibir a loucura em espetáculos públicos gradualmente desapareceu.

Em suma, nesse percurso através do mundo clássico, Foucault mostra que a loucura ficou reduzida a um simples espetáculo, a um teatro da desrazão.

O nascimento da clínica é para muitos um longo posfácio à História da loucura. Se na análise da loucura, o poder disciplinar já se delineia na passagem para a época asilar, na análise da clínica, Foucault (1977) sublinha o poder disciplinar do próprio olhar, descrito minuciosamente como um poder alienante e objetivante. E aí, se o tema é de índole sartriana - M. Jay (1989, p. 204) lembra o célebre capítulo sobre o olhar em $O$ ser e o nada - a sensibilização para essa temática veio a Foucault de Canguilhem - que na época se ocupava com a visão como modelo da cognição no pensamento ocidental. Quer dizer, O nascimento da clínica representa um segundo passo na crítica do visual. Escreve Foucault:

"O espaço da experiência parece identificar-se com o domínio do olhar atento, da vigilância empírica aberta apenas à evidencia dos conteúdos visíveis. O olho torna-se o depositário e a fonte da clareza; tem o poder de trazer à luz uma verdade que ele só recebe à medida que lhe deu à luz; abrindo-se sobre a verdade de uma primeira abertura: flexão que marca, a partir do mundo da clareza clássica, a passagem do 'Iluminismo' para o século XIX" (Foucault, 1977, p. XI-XII).

Esse novo olhar da medicina, entretanto, não é a visão interior que os cartesianos privilegiam em detrimento das percepções sensíveis. Sublinha, ao contrário, "o poder soberano do olhar empírico" que, agora, gira em torno dos volumes, das superfícies sólidas e opacas. E diz Foucault, "nenhuma luz poderá dissolvê-las nas verdades ideais; mas a aplicação do olhar sucessivamente as despertará e lhes dará objetividade. O olhar não é mais redutor, mas fundador do indivíduo em sua qualidade irredutível. E, assim, torna-se possível organizar em torno dele uma linguagem racional. O objeto do discurso 
FRAYZE-PEREIRA, João Augusto. Do império do olhar à arte de ver Tempo Social; Rev. Sociol. USP, S. Paulo, 7(1-2): 151-162, outubro de 1995.

também pode ser um sujeito, sem que as figuras da objetividade sejam por isso alteradas. Foi esta reorganização formal e em profundidade, mais do que o abandono das teorias e dos velhos sistemas, que criou a possibilidade de uma experiência clínica: ela levantou a velha proibição aristotélica; poderse-á, finalmente, pronunciar sobre o indivíduo um discurso de estrutura científica" (Foucault, 1977, p. XIII).

E bem mais adiante, Foucault continua: "O olhar penetra no espaço que ele estabeleceu como objetivo percorrer. A leitura clínica, em sua primeira forma, implicava um sujeito exterior e decifrador que, a partir e além do que soletrava, ordenava e definia parentescos. Na experiência anátomo-clínica, o olho médico deve ver o mal expor-se e dispor-se diante dele à medida que penetra no corpo, avança por entre seus volumes, contorna ou levanta as massas e desce em sua profundidade. A doença não é mais um feixe de características disseminadas pela superfície do corpo e ligadas entre si por concomitâncias e sucessões estatísticas observáveis; é um conjunto de formas e deformações, figuras, acidentes, elementos deslocados, destruídos ou modificados que se encadeiam uns com os outros, segundo uma geografia que se pode seguir passo a passo. Não é mais uma espécie patológica inserindo-se no corpo, onde é possível; é o próprio corpo tornando-se doente" (Foucault, 1977, p. 155).

Quer dizer, é a "figura do invisível-visível" que organiza a percepção clínica, anátomo-patológica, do médico. Porém, essa organização só foi possível porque a morte se integrou epistemologicamente à experiência médica, fazendo com que a doença se despregasse da contranatureza e viesse a tomar corpo no corpo vivo dos indivíduos.

É, sem dúvida, decisivo para a nossa cultura que o primeiro discurso científico enunciado por ela sobre o indivíduo tenha tido que passar por este momento da morte. É que o homem ocidental só pôde se constituir a seus próprios olhos como objeto de ciência, só se colocou no interior de sua linguagem, e só se deu, nela e por ela, uma existência discursiva por referência à sua própria destruição: da experiência da Desrazão nasceram todas as psicologias e a possibilidade mesma da psicologia; da colocação da morte no pensamento médico nasceu uma medicina que se dá como ciência do indivíduo. E de modo geral, a experiência da individualidade na cultura moderna está talvez ligada à da morte: dos cadáveres abertos de Bichat ao homem freudiano, uma relação obstinada com a morte prescreve ao universal sua face singular e dá à palavra de cada um o poder de ser indefinidamente ouvida; o indivíduo lhe deve um sentido que nele não se detém. A divisão que ela traça e a finitude, cuja marca ela impõe, ligam paradoxalmente a universalidade da linguagem à forma precária e insubstituível do indivíduo. O sensível, inesgotável à descrição, e que tantos séculos desejaram dissipar, encontra finalmente na morte a lei de seu discurso. Ela permite ver, em um espaço articulado pela linguagem, a profusão dos corpos e sua ordem simples (Foucault, 1977, p. 227).

Em suma, a visão desempenha nessa cadaverização da vida um pa- 
pel fundamental. Por ela não só "a morte abandona seu velho céu trágico, tornando-se o núcleo lírico do homem: sua invisível verdade, seu visível segredo", mas também é pela percepção da morte na vida que a medicina se torna importante para a constituição das ciências do homem: "importância que não é apenas metodológica, na medida em que ela diz respeito ao ser do homem como objeto de saber positivo" (Foucault, 1977, p. 227).

Ao abrir As palavras e as coisas com Velázquez e As Meninas, Foucault (1990) revela, dando continuidade à linha de pesquisa iniciada nas obras anteriores, até que ponto o humanismo repousa num campo epistemológico cujo princípio é visual. Escreve:

"Quando a história natural se torna biologia, quando a análise das riquezas se torna economia, quando sobretudo a reflexão sobre a linguagem se faz filologia e se desvanece esse discurso clássico onde o ser e a representação encontravam seu lugar-comum, então, no movimento profundo de uma tal mutação arqueológica o homem aparece com sua posição ambígua de objeto para um saber e de sujeito que conhece: soberano submisso, espectador olhado, surge ele aí, nesse lugar do Rei que, antecipadamente, lhe designavam Las Meninas, mas donde, durante longo tempo, sua presença real foi excluída. Como se nesse espaço vacante, em cuja direção estava voltado todo o quadro de Velázquez, mas que ele, contudo, só refletia pelo acaso de um espelho e como que por violação, todas as figuras de que se suspeitava a alternância, a exclusão recíproca, o entrelaçamento e a oscilação (o modelo, o pintor, o rei, o espectador) cessassem de súbito sua imperceptível dança, se imobilizassem numa figura plena e exigissem que fosse enfim reportado a um olhar de carne todo o espaço da representação" (Foucault, 1990, p. 328).

A substituição do espectador ausente (o rei) pelo espectador olhado (o homem) significa que o homem é ao mesmo tempo um "meta-sujeito" (pretensamente neutro) do conhecimento e o objeto desse conhecimento (Jay, 1989). E esse sujeito, é o que importa destacar, é função e não condição de uma visão todo poderosa, questão - a de ser observado por um olho desconhecido e onipresente - que é circunscrita com a análise do Panoptismo em Vigiar e punir (1991). Mas, se é nessa obra que Foucault chega a demonstrar o sutil mecanismo que permite à dominação ocular ultrapassar os limites de um soberano que tudo vê, desde a História da loucura, e sobretudo em O nascimento da clínica, o autor já punha o dedo na relação entre forças políticas e sociais, de um lado, e o poder objetivante do olhar, do outro, atribuindo, por exemplo, às reformas da Revolução Francesa o aparecimento da medicina moderna (Foucault, 1977, p 56-58).

Ora, é preciso observar que em todas essas pesquisas de Foucault há uma noção que dá suporte às suas análises. Trata-se da noção de espaço. E, como demonstra John Rajchman (1988, p. 102), uma grande parte das discussões de Foucault sobre o espaço é consagrada ao problema da visibilidade. Os espaços são destinados a fazer as coisas visíveis, visíveis de um modo específico. Com efeito, se ver, no trabalho de Foucault, tem o sentido de uma 
FRAYZE-PEREIRA, João Augusto. Do império do olhar à arte de ver Tempo Social; Rev. Sociol. USP, S. Paulo, 7(1-2): 151-162, outubro de 1995.

operação que abre para o "impensado visual”, nas histórias da Loucura, da Clínica e da Prisão são novos modos de ver que são revelados através de análises da construção de espaços. Hospitais, albergues, banhos públicos, escolas, prisões, museus, asilos - são espaços nos quais pode-se reconstituir a racionalidade de uma construção elaborada do que pode ser visto. São "espaços de uma visibilidade construída". E é a "arte da luz" e o visível que tais espaços dispõem que tornam evidentes certos aspectos de nós mesmos. Então, na análise da prisão, Foucault encontra uma inteligibilidade que a conecta às práticas pedagógicas, ao exército, às formas de divisão do trabalho, etc. Quer dizer, Foucault, segundo Deleuze (1988 p. 62), tem uma concepção do visível que é próxima à de Delaunay para quem a luz cria suas próprias formas e seus próprios movimentos. Delaunay dizia - "Cézanne quebrou a fruteira e nós não devemos colá-la novamente, como fizeram os cubistas". Ou seja, Foucault, com sua visão, rompe com o visível, mas circunda o evento com uma espécie de "poliedro de inteligibilidade" cujos lados se expandem indefinidamente em muitas direções (Rajchman, 1988, p. 107).

Ora, essa imagem visual do "poliedro de inteligibilidade" oferecida por Foucault aplica-se à sua própria obra. Seus escritos, como se sabe, mudam quanto a objetivos, objetos e métodos. Seu pensamento é pontuado por transformações no modo como concebe sua própria tarefa filosófica.

Em O uso dos prazeres (1984c), esse processo aparece como um exercício ou ascese, como um movimento de separação do filósofo em relação a si mesmo, através do ensaio que é "o corpo vivo da filosofia", uma experiência transformadora do modo de ver as coisas. Mas, Foucault acrescenta: há uma ironia nesse processo, pois o esforço para liberar alguém de si mesmo torna esse trabalho o seu próprio trabalho. Esse texto é belíssimo e vale a pena citá-lo por inteiro. Interrogando-se quanto aos motivos que o levaram a realizar sua obra, Foucault, então, escreve:

"Para alguns, espero, esse motivo poderá ser suficiente por ele mesmo. É a curiosidade-em todo caso, a única espécie de curiosidade que vale a pena ser praticada com um pouco de obstinação: não aquela que procura assimilar o que convém conhecer, mas a que permite separar-se de si mesmo. De que valeria a obstinação do saber se ele assegurasse apenas a aquisição dos conhecimentos e não, de certa maneira, e tanto quanto possível o descaminho daquele que conhece? Existem momentos na vida onde a questão de saber se se pode pensar diferentemente do que se pensa, e perceber diferentemente do que se vê, é indispensável para continuar a olhar ou a refletir. Talvez me digam que esses jogos consigo mesmo têm que permanecer nos bastidores: e que no máximo eles fazem parte desses trabalhos de preparação que de- 
saparecem por si sós a partir do momento em que produzem seus efeitos. Mas o que é filosofar hoje em dia - quero dizer, a atividade filosófica - senão o trabalho crítico do pensamento sobre o próprio pensamento? Se não consistir em tentar saber de que maneira e até onde seria possivel pensar diferentemente em vez de legitimar o que já se sabe ? Existe sempre algo de irrisório no discurso filosófico quando ele quer, do exterior, fazer a lei para os outros, dizerlhes onde está a sua verdade e de que maneira encontrá-la, ou quando pretende demonstrar-se por positividade ingênua: mas é seu direito explorar o que pode ser mudado, no seu próprio pensamento, através do exercício de um saber que lhe é estranho(...). Os estudos que se seguem, assim como outros que anteriormente empreendi, são estudos de 'história' pelos campos que tratam e pelas referências que assumem; mas não são trabalhos de 'historiador'. O que não quer dizer que eles resumam ou sintetizem o trabalho feito por outros; eles são - se quisermos encará-los do ponto de vista de sua 'pragmática' - o protocolo de um exercício que foi longo, hesitante, e que freqüentemente precisou se retomar e se corrigir. Um exercício filosófico: sua articulação foi a de saber em que medida o trabalho de pensar sua própria história pode liberar o pensamento daquilo que ele pensa silenciosamente, e permitirlhe pensar diferentemente. Teria eu razão em correr esses riscos? Não cabe a mim dizê-lo.(...) Tal é ironia desses esforços feitos a fim de mudar-se a maneira de ver, para modificar o horizonte daquilo que se conhece e para tentar distanciar-se um pouco. Levam eles, efetivamente, a pensar diferentemente? Talvez tenham, no máximo, permitido pensar diferentemente o que já se pensava e perceber o que se fez segundo um ângulo diferente e sob uma luz mais nítida. Acreditava-se tomar distância e no entanto fica-se na vertical de si mesmo. A viagem rejuvenesce as coisas e envelhece a relação consigo. Pareceme que seria melhor perceber agora de que maneira, um tanto cegamente, e por meio de fragmentos sucessivos e diferentes, eu me conduzi nessa empreitada de uma história da verdade: analisar, não os comportamentos, nem as idéias, não as sociedades, 
FRAYZE-PEREIRA, João Augusto. Do império do olhar à arte de ver Tempo Social; Rev. Sociol. USP, S. Paulo, 7(1-2): 151-162, outubro de 1995.

nem suas 'ideologias', mas as problematizações através das quais o ser se dá como podendo e devendo ser pensado, e as práticas a partir das quais essas problematizações se formam. A dimensão arqueológica da análise permite analisar as próprias formas da problematização; a dimensão genealógica, sua formação a partir das práticas e de suas modificações. Problematização da loucura e da doença a partir de práticas sociais e médicas, definindo um certo perfil de 'normalização'; problematização da vida, da linguagem e do trabalho em práticas discursivas obedecendo a certas regras 'epistêmicas'; problematização do crime e do comportamento criminoso a partir de certas práticas punitivas obedecendo a um modelo 'disciplinar'. Gostaria de mostrar, agora, de que maneira, na Antigüidade, a atividade e os prazeres sexuais foram problematizados através de práticas de si, pondo em jogo os critérios de uma 'estética da existência' ” (Foucault, 1984c, p. 13-15).

Em suma, a "nova luz" pela qual Foucault viu o que se realizava em sua obra foi a luz da "problematização". Analisar a história da loucura, da doença, do crime é ver tipos específicos de perigo ou problemas que evidenciam um modo novo e particular de concebê-los e de lidar com eles. Então, segundo Foucault (1984c), o que ele mesmo evidenciou em sua obra prévia é como as pessoas viram o perigo em tornar-se louco, doente, criminoso, como elas lidavam com esses perigos e como eram tornados visíveis ou espacializados no conhecimento e na ação.

O que sempre esteve em questão é "através de quais jogos de verdade o homem se dá seu ser próprio a pensar quando se percebe como louco, quando se olha doente, quando reflete sobre si como ser vivo, ser falante, e ser trabalhador, quando ele se julga e se pune enquanto criminoso? Através de quais jogos de verdade o ser humano se reconheceu como homem de desejo?'(Foucault, 1984c, p. 12).

Essa nova perspectiva da "problematização" põe o foco sobre as preocupações éticas do filósofo e sobre o caráter autobiográfico de sua obra. Nos últimos cinco anos de vida, em duas entrevistas, declarou:

$1^{\circ}$ ) "Cada vez que eu tentei fazer um trabalho teórico foi tendo por base elementos de minha própria experiência - sempre nas relações que eu via ocorrerem à minha volta. Foi na verdade porque eu pensei que reconhecia algo arruinado ou disfuncional no que eu via, quer nas instituições com as quais eu lidava, quer nas minhas relações com os outros, que eu realizei uma particular parte de uma obra que são diferentes fragmentos de uma autobiografia" (Foucault, 1981, p.30-31).

$2^{\circ}$ ) "Eu gostaria de fazer a genealogia dos problemas, das proble- 
máticas. Meu ponto é que nem tudo é ruim, mas que tudo é perigoso, e isso não é a mesma coisa que dizer que é mau. Se tudo é perigoso, então, temos algo a fazer" (Hoy, 1986, p. 343).

Essa "arte de ver os problemas", como aparece designada em sua última obra, Foucault (1984c) relaciona à "escolha político ética" que um indivíduo faz, "determinando qual é o real perigo" a ser enfrentado. A escolha de ver aquilo contra o qual nós temos de lutar para nos libertarmos ( e nos libertarmos de nós mesmos) é uma escolha perigosa, porque é um salto no ar: não temos, a priori, qualquer imagem dessa liberdade. Nesse caso, o perigo não vem do risco de falharmos em nos tornarmos o que estamos destinados a ser, mas que possamos ser apenas aquilo que podemos ver de nós mesmos. A beleza de nossa liberdade está, portanto, no perigo. Quer dizer, segundo John Rajchman (1988, p.114), o perigo da beleza dá margem a uma obra de si na qual ver o que se faria é mudar o próprio modo de vida, mudança que envolve o próprio modo de ver. Ou seja, muda-se a si mesmo quando um indivíduo vem a ver o que é perigoso na existência de alguém e chega a ver o que é perigoso na mudança de si mesmo. E para Foucault (1984c, p.14), definir as condições nas quais o ser humano "problematiza" o que ele é, e o mundo no qual ele vive, é a tarefa de uma história do pensamento.

Ora, nesse momento, se não soubéssemos que essas idéias são de Foucault, facilmente poderíamos atribuí-las a certos psicanalistas. No entanto, para evitar estremecimentos, mal-entendidos, podemos torná-las mais precisas, perguntando - que é pensar?

Quanto a isso Foucault é explícito: pensar é problematizar. Diríamos nós, em Psicanálise, é interrogar. Certamente, como diz Deleuze (1988, p.124), uma coisa pelo menos perturba Foucault: o pensamento. E isto é pertubador porque, pensar é fazer com que o ver atinja o seu limite próprio e o falar atinja o seu, de tal forma que os dois estejam no limite comum que os relaciona um ao outro, separando-os. Pensaré, portanto, aquilo que se faz no entremeio do ver e do falar. Nessa medida, afirmou Foucault, o pensamento não se confunde com o conjunto de representações que subjaz a um certo comportamento, nem com o domínio das atitudes que podem determinar esse comportamento. "O pensamento não é o que habita uma certa conduta e dá a ela seu significado; melhor do que isso, é o que permite a alguém voltar atrás quanto a esse modo de agir ou reagir, apresentá-lo como um objeto de pensamento e interrogá-lo quanto ao seu sentido, suas condições e seus propósitos. Pensamento é, portanto, liberdade quanto àquilo que se faz, o movimento pelo qual nos diferenciamos dessa ação, a estabelecemos como um objeto e refletimos sobre ela como um problema"(Foucault, 1984b, p. 388).

Ora, se Foucault é aquele que tem paixão pelo ver, segundo Deleuze (1988, p. 60), o que o define acima de tudo é a voz, além dos olhos. Quer dizer - os olhos e a voz - termos que balizam o pensamento de um filósofo encarnado que jamais deixou de ser um vidente (a expressão é de Deleuze), ao mesmo tempo que marcou a Filosofia com um novo estilo de enunciado, as duas coi- 
FRAYZE-PEREIRA, João Augusto. Do império do olhar à arte de ver Tempo Social; Rev. Sociol. USP, S. Paulo, 7(1-2): 151-162, outubro de 1995.

sas num passo diferente, num ritmo duplo.

Equem desejar ver esse "novo estilo" como arte, novamente para evitar equívocos, é preciso ter em mente as esclarecedoras palavras de Foucault, na última entrevista que nos deixou:

"O que me espanta é que em nossa sociedade a arte só tenha relação com os objetos e não com os indivíduos ou com a vida; e também que a arte seja um domínio especializado, o domínio dos especialistas que são os artistas. Mas a vida de todo indivíduo não poderia ser uma obra de arte? Por que um quadro ou uma casa são objetos artísticos, mas não a nossa vida?"(Foucault, 1984a, p. 331).

Entre a escuta dessa fala e o que ela nos dá a ver, instala-se o exercício do pensamento.

Recebido para publicação em agosto/1995

FRAYZE-PEREIRA, João Augusto. From the empire of looking to the art of seeing. Tempo Social; Rev. Sociol. USP, S. Paulo, 7(1-2): 151-162, october 1995.

ABSTRACT: Martin Jay (1986) and John Rajchman (1988) have written essays about the space of vision and of the visual in Foucault's philosophical work. Although the theme is the same the author's perspectives are very different. Thus, concernig these two essays, the purpose of this article is to circumscribe another vision about the empire of the gaze and the art of seeing in Foucault's writings. The relationship between vision and thought is

UNITERMS:

Foucault, looking, vision, vision-thought, art of seeing. considered under the perspective of problematizations.

\section{REFERÊNCIAS BIBLIOGRÁFICAS}

Deleuze, G. (1988) Foucault. São Paulo, Ed. Brasiliense.

ERIBOn, D. (1990) Michel Foucault, uma Biografia. São Paulo, Cia. das Letras. Foucault, M. (1961) Histoire de la folie. Paris, Plon. . (1963) Naissance de la clinique. Paris, PUF. .(1966) Les mots et les choses. Paris, Gallimard. . (1972) Histoire de la folie. $2^{\mathrm{ème}}$ ed. Paris, Gallimard. . (1977) O nascimento da clínica. Rio de Janeiro, Forense-Universitária.

. (1981) Est-il donc important de penser? Libération, maio 30-31. 
. (1984a) Entretien avec Hubert L. Dreyfus et Paul Rabinow. In: Dreyfus, H. \& Rabinow, P. Michel Foucault, un parcours philosophique. Paris, Gallimard. p. 322-346.

. (1984b) Polemics, politics and problematizations: an interview with Michel Foucault. In: RABINOw, P(ed.). The Foucault Reader. New York, Pantheon Books. p. 381-390.

. (1984c) Uso dos prazeres. Rio de Janeiro. Ed. Graal Ltda.

. (1990) As palavras e as coisas. São Paulo, Martins Fontes.

. (1991) Vigiar e punir. $8^{\mathrm{a}}$ ed. Petrópolis, Ed. Vozes.

Frayse-Pereira, J. A. (1995) Olho d'água. Arte e loucura em exposição. São Paulo, Ed. Escuta/FAPESP.

Hoy, D.C. (ed.). (1986) Foucault: a Critical Reader. Londres, Basil Blackwell.

JAY, M. (1986) In the empire of the gaze: Foucault and the denigration of vision in twentieth-century french thought. In: Hoy, D.C. (ed.). Foucault: a Critical Reader. Londres, Basil Blackwell.

. (1989) Sous l'empire du regard: Foucault et le declin du visuel dans la pensée française du vingtième siécle. In: Hoy, D.C. (ed.). Michel Foucault - lectures critiques. Bruxelles, De Boeck - Wesmael S.A. p. $195-223$.

Rajchman, J. (1988) Foucault's Art of Seeing. October, 44: 89-117. 